\title{
COASTRO: @N ASTRONOMY CONDO - TEACHERS' ATTITUDES AND EPISTEMOLOGICAL BELIEFS TOWARDS SCIENCE IN A CITIZEN SCIENCE PROJECT
}

\author{
Ilídio André Costa ${ }^{1}$, Carla Morais ${ }^{2}$, \& Mário João P. F. G. Monteiro ${ }^{3}$ \\ ${ }^{1}$ Agrupamento de Escolas de Santa Bárbara, Planetário do Porto - Centro Ciência Viva, Faculdade de \\ Ciências da Universidade do Porto, Instituto de Astrofisica e Ciência do Espaço da Universidade do \\ Porto (Portugal) \\ ${ }^{2}$ Centro de Investigação em Química da Universidade do Porto, Unidade de Ensino das Ciências, \\ Departamento de Química e Bioquímica, Faculdade de Ciências da Universidade do Porto (Portugal) \\ ${ }^{3}$ Departamento de Física e Astronomia da Faculdade de Ciências da Universidade do Porto, e Instituto \\ de Astrofisica e Ciência do Espaço da Universidade do Porto (Portugal)
}

\begin{abstract}
It is common to consider an attitude as a hypothetical construct related to a tendency that is expressed by evaluating a particular entity with some degree of favour or disfavour. In the case of attitudes toward science, these cannot be isolated from the understanding of science processes: the path to produce, refute and change knowledge. Thus, it is critical to promote public engagement with science-astronomy and technology (PESaT) with the goal of understanding contents, but also of understanding what science is and how it is built.

In this context CoAstro: @n Astronomy Condo emerged - a citizen science project that starts with the involvement of elementary school teachers with the Research Group on the "Origin and Evolution of Stars and Planets" at the Instituto de Astrofísica e Ciências do Espaço (IA). CoAstro has directly reached about a thousand participants (including students, parents, astronomers and science disseminators).

To study teachers' attitudes and epistemological beliefs towards science, as well as to analyse any changes promoted by CoAstro, a semi-structured interview (EAC) based on the Scientific Attitude Instrument and on the Nature of Scientific Knowledge Scale was prepared. After the translation of these instruments into Portuguese, scientific and linguistic validation by experts was made.

The EAC was performed before (EI) and after (EII) the development of the CoAstro. It involved 9 elementary teachers ( 8 females and 1 male, with an average age of 44.8 years) with no degree in science and who volunteered to participate in CoAstro.

The results show that there has been an increase of interest in astronomy that can be substantiated, namely by: i) a greater demand for news, motivated by intrinsic pleasure in astronomy (and not merely by professional necessity, as happened in EI) that became a more intelligible science; ii) a greater interest in seminars, classes or lectures; iii) an increase of interest in citizen science projects. On the other hand, teachers considered to be more knowledgeable about science, allowing them to make greater use of this knowledge in their daily lives and to assess claims about science.

Epistemological beliefs data reveal that the time between EI and EII reinforced the conviction: i) that it is possible to judge the applications of scientific knowledge, but not knowledge itself; ii) that creativity is associated with science, essentially at the beginning of the scientific process; iii) that repeatability and consistency of results are conditions for the validation of scientific knowledge; vi) the strong relationship between the various scientific fields.

For teachers, since EI, scientific knowledge is provisional and a consequence of its predecessor. The concept of parsimony that was completely strange to teachers has come to be understood, but the tendency to consider scientific knowledge parsimonious is not univocal.

Analysing the evolution of teachers' attitudes and epistemological beliefs will help to better assess CoAstro, by measuring the relevance of a citizen science project (which combines remote interactions with systematic bilateral interactions) for a more holistic awareness and understanding of knowledge and scientific processes in Astronomy.
\end{abstract}

Keywords: Citizen science, science communication, epistemological belief, attitudes towards science. 


\section{Introduction}

Science communication can be understood as any act that aims to promote one or more of the following paradigms (Burns, O'Connor, \& Stocklmayer, 2003; Oliveira \& Carvalho, 2015): i) public awareness of science (PAS) - predominantly about attitudes toward science; ii) public understanding of science (PUS) - understanding of science content, methods of inquiry and science as a social enterprise; iii) public engagement with science and technology (PEST) - the engagement will correspond to an involvement of non-specialists in scientific-technological subjects, under a philosophy of reciprocal learning. Such desiderate appears to be most easily attainable if citizens can be directly involved in the process of scientific production - citizen science - in order to understand contents, but also what science is and how it is built. That was done in "CoAstro: @n Astronomy Condo". In this paper, when we discuss the results of an astronomy project, we will use the acronym PESaT - public engagement with science-astronomy and technology.

\subsection{CoAstro - a citizen science project}

The term citizen science is used to refer the public engagement in different stages of scientific processes. This collaborative concept, between astronomers and volunteers, is becoming an increasingly popular space in non-formal science education (Price \& Lee, 2013). Indeed, citizen science can easily create a win-win context: it attracts more researchers to science communication and, on the other hand, allows the public to participate directly in scientific processes (Riesch \& Potter, 2014).

Thus, CoAstro defines itself as a citizen science project which, during one school year (2018/2019), had the participation of four astronomers, from the Instituto de Astrofísica e Ciências do Espaço (IA), in Portugal, nine elementary school teachers, four science communicators and one mediator (these belonging to the Porto Planetarium - Ciência Viva Center - PP-CCV). Under this project the public engagement with science-astronomy and technology (PESaT) was made with the goal of understanding contents, but also to promote "positive" attitudes and epistemological beliefs towards science.

CoAstro was organized in eight main work packages. One took a central role in the process: the involvement of elementary school teachers, with the Research Group on the "Origin and Evolution of Stars and Planets" at IA. This followed a collaborative model of citizen science (Brandt, Shirk, Jordan, Ballard, \& Tomasek, 2010): data collection was accompanied by their analysis. This allowed the project to be extended to the school community with the engagement of approximately one thousand persons.

To engage teachers in astronomy research, two subprojects were developed in CoAstro: "Stars" (aiming the analysis of a standard stellar spectrum in order to allow the determination of the composition of 57000 stars and the characterization of their brightness, using Data Release 2 from the European Space Agency - ESA - GAIA Mission) and "Planets" (aiming the production of a planetary transit video, using Python program and the analysis of light curves to signal the presence of potential exoplanets).

CoAstro assumed, from its conception that one of its objectives would be to work attitudes and epistemological beliefs towards science. Thus, it would be necessary to analyse the teachers' attitudes at the beginning and end of the project, in order to understand CoAstro's contributions to this process. It is in this context that we will now present the process that led to that assessment.

\subsection{Attitudes and epistemological beliefs towards science}

The individual science conceptions may be one of the primary conditioning sources of attitudes towards science and visions about how it is built (Tytler, 2014). Such attitudes towards science are define by Osborne, Simon, and Collins (2003, p. 1053) as "the feelings, beliefs and values held about an object that may be the enterprise of science, school science, the impact of science on society or scientists themselves". Basically, these authors assume that the concept established is no more than the synthesis of the set of affective behaviours previously listed by Klopfer (1971): the presence of favourable attitudes towards science and scientists; the acceptance of scientific methods as a way of thinking; the adoption of scientific attitudes; the pleasure associated with scientific learning opportunities; interest in science and related activities; and the interest in pursuing scientific careers. Miller (1983) considers attitudes towards science as an element of scientific literacy: attitudes towards science and knowledge (towards activities related to science) - the social impact of science on the individual and on society itself. However, he does not isolate this domain from the understanding of scientific processes: the nature of science. For Ozgelen (2012, p. 104) this refers to "epistemology and values and beliefs for scientific knowledge and how that knowledge is developed, refuted, and changed". Thus, Price and Lee (2013) prefer to designate this domain as epistemological beliefs about science.

This seemed to us to be the understanding that best represents what we are trying to measure in the present work. Thus, we will designate the two attitudinal components analysed using the following nomenclature: i) attitudes towards science; ii) epistemological beliefs. 


\section{Methodology}

In this section, we will present the attitudes instruments and the process that led to the EAC's script.

\subsection{Attitudes instruments for CoAstro}

To study teachers' attitudes and epistemological beliefs towards science, as well as to analyse any changes promoted by CoAstro, a semi-structured interview (with the Portuguese acronym EAC), based on the Scientific Attitude Instrument (SAI) and on the Shortened Nature of Scientific Knowledge Scale (SNSKS) was prepared.

SAI is an instrument presented by Price and Lee (2013), built due to the lack of attitude instruments properly developed outside the educational context. That was our motivation to build EAC based in SAI: SAI is an attitude instrument assembled to match the characteristics of an older citizen science audience. It is "constrained in length, focus on the use of science in everyday life, and include questions that would measure behaviour unique to a citizen science audience" (Price \& Lee, 2013, p. 780).

SNSKS was based on the Nature of Scientific Knowledge Scale (NSKS) established by Rubba and Andersen (1978). The items in the original NSKS included 48 items grouped into six categories of the nature of science (amoral, creative, developmental, parsimonious, testable, and unified). Each category included four positively stated items and four negatively stated items. The SNSKS kept the number of categories but reduced to four the number of items per category. That was made in response to the pilot study: the authors omitted all negative items. This shortening was necessary due to the resistance of Price \& Lee's citizen science participants: they rebelled on the public discussion forums of the project. This is a common problem in citizen science (Price \& Lee, 2013). SNSKS was chosen over other attitudes instruments because: i) it is based on a survey instrument with extensive pedigree (NSKS); ii) it was experimented in citizens science projects; iii) its application, simultaneously with SAI, was already tested (Price \& Lee, 2013).

SAI has nine items and SNSKS twenty-four items answered with a 5-point Likert scale consisting of Strongly Disagree, Disagree, Neutral, Agree, and Strongly Agree categories. SAI's reliability $(\alpha=0.95)$ and SNSKS' reliability $(\alpha=0.94)$ were high. SNSKS was in general agreement with previous validation work on the original NSKS instrument, despite its shortened length.

A total of 3180 participants completed the pre-test (with SAI and SNSKS simultaneously) made by Price $\&$ Lee. They were invited to take the post-test after 6 months: 365 participants complete that task.

\subsection{Building EAC's interview script}

The above description justifies the choice of the SAI and SNSKS, as the basis for our interview about attitudes and epistemological beliefs (EAC), done to teachers involved in CoAstro. Therefore, in this section we will characterize the EAC respondents and the whole process that, starting from SAI and SNSKS, led to the adaptation and application of the EAC used in the CoAstro project.

The option for a semi-structured interview was made due to the number of CoAstro teachers: nine. Therefore, we decided to adapt SAI and SNSKS and built an interview script based on them.

In order to produce the EAC's interview script we started by translating SAI and SNSKS from English into Portuguese. This first translation was the subject of a scientific analysis by a Science Education and Communication expert. In this analysis, the expert verified the need to make some adjustments, in order to avoid changing the meaning of the SAI/SNSKS.

Subsequently, a graduate person, working in the United Kingdom for seven years, made the retroversion of that translation. This process did not reveal any important difference between the translation and the original SAI/SNSKS.

This whole process of translation, analysis, and retroversion led to a first stabilized version of the EAC that allowed us to proceed to the next phase: the interview script. The same Science Teaching and Dissemination expert also analysed it. With minor changes needed, we had the final version of EAC script. This script has the same number of question as its predecessors (SAI/SNSKS): we only translated them and validated that translation.

\subsection{EAC's participants}

EAC's participants were 45 years old, on average. Eight respondents were female and one male. Four teachers completed high school in urban areas, two in suburban areas and three in rural areas. However, at the time of the first interview five worked in suburban schools, three in urban schools and only one in a rural school. All teachers stated that they had never taken any specific astronomy course or participated in any astronomy initiative. For three of these teachers, it was CoAstro that provided the first contact with the Porto Planetarium - Ciência Viva Center (PP-CCV). 


\subsection{EAC's application}

The first moment of interview (EI) ran between $23^{\text {th }}$ of January and $18^{\text {th }}$ of February. They took place on a "familiar" context for the teachers (school, coffee shop, their home...). At that point, teachers only have learned about CoAstro objectives. The interview was recorded with the interviewee's authorization. All nine interviews followed a common dynamic: the interviewer read each statement of the interview script; the interviewee positioned himself according to a level on the Likert scale and justified, when he deemed it was necessary, his answer. The interviewer, also when necessary, asked for clarification of any idea presented by the interviewee. Thus, 9 interviews were completed.

With the same procedure and in the same application context, the second moment of interview (EII) ran between $20^{\text {th }}$ of September and $8^{\text {th }}$ of October. All the nine teachers completed EII, by two months after the end of the project.

\section{Results}

We start by recalling that the data collected through the EAC had as objectives: i) to know what are the attitudes towards science and the epistemological beliefs of the elementary school teachers, involved in CoAstro; ii) verify if their participation in CoAstro has modified those same attitudes and beliefs.

Based on the interview script and on its objectives, an analysis framework was produced with categories (A and B) and subcategories (A1 and A2; B1 to B6), from which the content analysis of the interviews was made: A. Attitudes towards science (A1. Interest and proactivity; A2. Understanding and use of scientific knowledge); B. Epistemological beliefs (B1. Amorality of scientific knowledge and its application; B2. Creativity in science; B3. Knowledge construction process; B4. Parsimony in science; B5. Validation of knowledge; B6. Interdisciplinarity of science). The following summarizes some of the main results, supported by excerpts from the conducted interviews, which we translated from Portuguese to English.

Regarding category A, the results showed that from EI to EII, there was an increase in science interest, in citizen science projects, more specifically in those astronomy based; "I occasionally find myself going to TESS [Transiting Exoplanet Survey Satellite], something I never did before, (Teacher 3)". However, that was made without high levels of proactivity when looking for news: "I don't make it my banner to go to the newspaper..., but if it has [some about astronomy], I see, I read and I'm interested, something that didn't happen before" (Teacher 6). Teachers said that they were more knowledgeable about science (although little knowledgeable), which allows them to make greater use of that knowledge to evaluate claims made about science and to place it in their daily lives (mainly in terms of their teaching practice): "In terms of astronomy yes [changed], ... because there was very little what I knew [to be able to assess scientific knowledge] ..., but today I already operate in another way "(Teacher 8).

The elapsed period between EI and EII helped to reinforce the conviction that it is possible to judge the applications of scientific knowledge, but not knowledge itself (B1 category). The reinforcement of the pre-existing belief regarding creativity in science (B2 category) was also found from EI to EII. However, for most of the interviewers, creativity in science exists only at the beginning of the scientific process: "In scientific theory we can perceive the creative way in which the scientist got there, but the concept itself, the law and theory, for me, does not have creativity" (Teacher 2). There was no change in most participants, regarding the understanding of how scientific knowledge is constructed (B3 category). The interviewers already considered at EI that scientific knowledge results from past knowledge, valid in the historic context in which was produced; it is provisional, because even at the time of its acceptance it can include errors. The concept of parsimony (B4 category) was unknown to teachers. At EII, the concept was already clear, for teachers, but the tendency to associate it with scientific knowledge is not univocal. Even so, in the period between EI and EII this issue was clearly pondered by teachers.

It is possible to establish a direct relationship between participation in CoAstro and the reinforcing of the belief that repeatability and consistency of results are conditions for the validation of scientific knowledge (B5 category): "In different parts of the world... [the] scientists will have to reach equivalent results again" (Teacher 8). In the EII, there is an almost generalized idea that observations allow the laws, theories and scientific concepts to be tested.

Most teachers, already in EI, had an interdisciplinary view of science (B6 category), although only between some specific sciences (such as Physics and Chemistry). That interdisciplinary understanding of science was unanimous, reinforced and universalized, at the time of the EIIs and already among all sciences (biology, chemistry and physics): "Biology also has chemistry and it also has physics... I think they are interconnected with each other" (Teacher 7). 


\section{Conclusions}

For the content analysis categories defined, the influence of CoAstro in B3 was not seen only in B3 (knowledge building process) and in B5 (parsimony in science). Although, this last concept became known to teachers (after CoAstro), it was not uniquely associated with scientific processes. In all others categories, there are reinforcement of beliefs, an increase in science interest and in the understanding and use of scientific knowledge. The increase in proactivity was not significant, perhaps due to the subscription of new resources (such as newsletters) between EI and EII, or because teachers started to resort to means (such as content suggestions from online services and software companies) in which the news are presented, according to their research interests.

A comparison with Price and Lee's results (2013), although it may be done, requires some caution, because: i) the data were treated in a quantitative way; ii) SAI/SNSKS were provided when participants first registered via the web site of the project - interest in astronomy and science was, already, very high; iii) the nature of the Citizen Sky Project - a web based project aiming the report, by volunteers, of visual brightness estimates for a multiple star system ( $\varepsilon$ Aurigae) - is very different from CoAstro's nature.

Thus, as Price and Lee's results we detected a significant change in the scientific attitude. Other citizen science projects have not reported any change in scientific attitude (Brossard, Lewenstein, $\&$ Bonney, 2005). Also, as Price and Lee our results suggest that epistemological beliefs were reinforced, rather than restructured. This alignment with Price and Lee's results is a very important aspect because they were the firsts in the literature to show a change in epistemological beliefs through a citizen science project.

Therefore, our results reveal that a citizen science project, built on a model such as CoAstro's, supported by a collaborative view of citizen science and aligned with a PEST paradigm, can effectively contribute to the increase of interest, understanding and use of science knowledge and the reinforcement of correct epistemological beliefs. For this purpose, the key elements appear to be the involvement of teachers in astronomy research that motivated participants to undertake autonomous and, therefore, more meaningful and lasting learnings.

\section{References}

Brandt, C., Shirk, J., Jordan, R., Ballard, H., \& Tomasek, T. (2010). Beyond citizen science: Science learning and public participation in environmental research. Paper presented at the Symposium conducted at the meeting of the National Association of Research in Science Teaching, Philadelphia.

Brossard, D., Lewenstein, B., \& Bonney, R. (2005). Scientific knowledge and attitude change: The impact of a citizen science project. International Journal of Science Education, 27(9), 1099-1121.

Burns, T. W., O'Connor, D. J., \& Stocklmayer, S. M. (2003). Science communication: a contemporary definition. Public Understanding of Science, 12(2), 183-202.

Klopfer, L. E. (1971). Evaluation of learning in science. In J. T. H. B. S. Bloom, G. F. Madaus (Ed.), Handbook of formative and summative evaluation of student learning. London: McGraw-Hill.

Miller, J. D. (1983). Scientific literacy: A conceptual and empirical review. Daedalus, 29-48.

Oliveira, L. T. d., \& Carvalho, A. (2015). Public Engagement with Science and Technology: contributos para a definição do conceito e a análise da sua aplicação no contexto português. Observatorio $\left(O B S^{*}\right), 9(3), 155-178$.

Osborne, J., Simon, S., \& Collins, S. (2003). Attitudes towards science: a review of the literature and its implications. International Journal of Science Education, 25(9), 1049-1079.

Ozgelen, S. (2012). Exploring the Relationships among Epistemological Beliefs, Metacognitive Awareness and Nature of Science. International Journal of Environmental and Science Education, $7(3), 409-431$.

Price, C. A., \& Lee, H. S. (2013). Changes in participants' scientific attitudes and epistemological beliefs during an astronomical citizen science project. Journal of Research in Science Teaching, 50(7), 773-801.

Riesch, H., \& Potter, C. (2014). Citizen science as seen by scientists: Methodological, epistemological and ethical dimensions. Public Understanding of Science, 23(1), 107-120.

Rubba, P. A., \& Andersen, H. O. (1978). Development of an instrument to assess secondary school students understanding of the nature of scientific knowledge. Science Education, 62(4), 449-458.

Tytler, R. (2014). Attitudes, identity, and aspirations toward science. In Handbook of Research on Science Education, Volume II (pp. 96-117): Routledge. 